Philosophy

\title{
Equality, value pluralism and relevance: Is luck egalitarianism in one way good, but not all things considered?
}

\section{Tim Meijers \& Pierre-Etienne Vandamme}

To cite this article: Tim Meijers \& Pierre-Etienne Vandamme (2018): Equality, value pluralism and relevance: Is luck egalitarianism in one way good, but not all things considered?, Critical Review of International Social and Political Philosophy, DOI: 10.1080/13698230.2018.1438804

To link to this article: https://doi.org/10.1080/13698230.2018.1438804

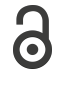

(C) 2018 The Author(s). Published by Informa

UK Limited, trading as Taylor \& Francis Group

曲 Published online: 18 Feb 2018.

Submit your article to this journal $\widetilde{ }$

Џ Article views: 470

View Crossmark data $\widetilde{\nearrow}$ 


\title{
Equality, value pluralism and relevance: Is luck egalitarianism in one way good, but not all things considered?
}

\author{
Tim Meijers ${ }^{\mathrm{a}, \mathrm{b}}$ and Pierre-Etienne Vandamme ${ }^{\mathrm{c}}$ \\ ${ }^{a}$ Institute for Philosophy, Leiden University, Leiden, The Netherlands; ${ }^{b}$ Department of Philosophy \\ and Religious Studies, Utrecht University, Utrecht, The Netherlands; ' Hoover Chair of Economic \\ and Social Ethics, University of Louvain (UCL), Louvain-la-Neuve, Belgium
}

\begin{abstract}
Some luck egalitarians argue that justice is just one value among others and is thus not necessarily what we should strive for in order to make the world better. Yet, by focusing on only one dimension of what matters - luck equality - it proves very difficult to draw political implications in cases where several values are in tension. We believe that normative political philosophy must have the ambition to guide political action. Hence, in this paper we make a negative and a positive point. Negatively, we argue that the inability to offer recommendations on what to strive for potentially weakens Kasper Lippert-Rasmussen's account of luck egalitarianism. In order not to be irrelevant for political practice, a more serviceable version of luck egalitarianism that would allow for all-things-considered judgments is needed. Positively, we examine two possible routes toward such a view. One would be to stick to pluralism, but to discuss possible clashes and find a rule of regulation in each case. Another would consist in giving up value pluralism by identifying an over-arching value or principle that would arbitrate between different values. We suggest that Lippert-Rasmussen's foundation of equality carries the potential for such an overarching principle.
\end{abstract}

KEYWORDS Value pluralism; luck egalitarianism; equality; justice; political action

\section{Introduction}

Normative political philosophy must have the ambition, in one way or another, to guide political action. Theories of justice, in particular, generally present themselves as a utopian agenda defining the horizon of the quest for social justice. This ambition can be threatened by certain appeals to value pluralism - the view

\section{CONTACT Tim Meijers T.meijers@phil.leidenuniv.nl}

(c) 2018 The Author(s). Published by Informa UK Limited, trading as Taylor \& Francis Group.

This is an Open Access article distributed under the terms of the Creative Commons Attribution-NonCommercialNoDerivatives License (http://creativecommons.org/licenses/by-nc-nd/4.0/), which permits non-commercial re-use, distribution, and reproduction in any medium, provided the original work is properly cited, and is not altered, transformed, or built upon in any way. 
that there is a plurality of values which inevitably conflict in a way that cannot be arbitrated once and for all by the political philosopher. Faced with conflicting values, some philosophers claim that final decisions have to be made in practice and philosophy is confined to the modest role of clarifying important values.

Isaiah Berlin is probably the most famous defender of such value pluralism and there now exists a vast literature on the alleged clash between equality and freedom, which he took to be insuperable. John Rawls proposed one of the most elegant answers to this challenge through his lexicographically ordered principles of justice. His difference principle also offers a nice way of articulating the values of fairness and efficiency. Because his principles of justice incorporate efficiency considerations, he can affirm at the beginning of his Theory of Justice that 'laws and institutions no matter how efficient and well-arranged must be reformed or abolished if they are unjust' because justice is 'the first virtue of social institutions' (Rawls, 1971, p. 3).

Luck egalitarians reject the Rawlsian approach for a variety of reasons and defend a potentially more egalitarian view of justice, which accepts only those inequalities that can be traced back to (genuine) choices. ${ }^{1}$ Yet some of them remain silent on how the equality they defend relates to other values such as freedom, efficiency or respect. This is the case, for example, with G. A. Cohen, who carefully distinguishes judgments about justice from all-things-considered judgments. Kasper Lippert-Rasmussen seems to endorse a relatively similar approach to luck egalitarianism. Fortunately, he devotes the last chapter of his book to the relation between luck egalitarian equality and other values. We argue, however, that the answer he provides is unsatisfying and fails to live up to the ambition that Lippert-Rasmussen sets himself at the beginning of his book, i.e. showing why, despite many criticisms, 'luck egalitarianism remains a strong candidate for a plausible theory of distributive justice' (Lippert-Rasmussen, 2015, pp. xiv, xv). The reason is that in order not to be irrelevant for political practice, which we believe to be crucial for a plausible theory of justice, such a theory must provide guidance to all-things-considered judgments. Yet, on most issues, it seems to us that Lippert-Rasmussen's luck egalitarianism does not.

The section 'Luck egalitarianism and value pluralism' considers the relation between luck egalitarianism and other values in the works of Cohen and LippertRasmussen and the rationale behind the isolation of equality from other values. It argues that this move has a valuable critical potential but threatens luck egalitarianism with practical irrelevance. In 'What is the point of luck egalitarianism?' we critically assess the defensive strategy endorsed by Lippert-Rasmussen when faced with this objection of irrelevance, which consists in downplaying the role of a theory of justice. In 'Pluralism with rules of regulation' we suggest that one can stick to pluralism and yet remain action-guiding by proposing a rule of regulation for each serious clash of values. Finally, in 'Valuable for what?' we explore a way of building all-things-considered judgments on an overarching value. In this way, we aim at providing an internal critique of luck egalitarianism - whose 
intuition of justice is here assumed to be valid - and a constructive critique, by suggesting two routes open to luck egalitarianism to regain relevance.

\section{Luck egalitarianism and value pluralism}

Value pluralism is not endorsed by all luck egalitarians. Yet it grounds one of its most famous versions: the one defended by G. A. Cohen. ${ }^{2}$ Cohen believes that inequalities that cannot be traced back to different choices are pro tanto unjust. Nonetheless, he warns, this does not entail 'that such unjust inequality cannot be part of a package of policy that is, all-things-considered, superior to any other (because values other than justice weigh in its favor)' (Cohen, 2008, p. 7).

Apart from the last chapter called 'Other Values', Lippert-Rasmussen also discusses value pluralism when facing the so-called leveling down objection to (luck) egalitarianism (pp. 129-150). This objection suggests that equality is not by itself an attractive ideal as it would entail that we should seek to make everyone equal even when this means making everyone worse off than they currently are. After having examined several egalitarian responses to this objection, LippertRasmussen adopts what he coins as the egalitarian 'bullish stance': 'a state in which everyone is worse off, but equally well-off, is in one respect - though not all-things-considered - better than one in which everyone is better off, though unequally so' (p. 149). This response is only available to those who accept value pluralism, or at least doubt the plausibility of a unified theory of value, because it assumes we can talk about goodness in reference to only one value among many. Monists would say that this state of affairs has to be either desirable or undesirable, better or worse, because they take value judgments to be about what is, taking on board different considerations, required all-things-considered. For example, someone who defends human flourishing as the overarching value will surely believe that a state in which everyone flourishes is more desirable than one in which less people do, whatever the loss of equality.

What value pluralists want to make room for is the distinction, in Cohen (2008)'s words, between fundamental principles of justice on the one hand, which are independent from facts and, on the other hand, rules of regulation which are facts-sensitive and weigh the value of justice against other values to produce an all-things-considered judgment. This distinction, which LippertRasmussen endorses, allows disentangling considerations of justice from other considerations such as efficiency or stability. Its appeal lies in the ability to rescue the value of justice from factual assumptions and approaches of justice (constructivism is Cohen's main target) that tend to alter it, or to mix it with other considerations at the cost of intellectual clarity.

Why is it important to distinguish justice from all-things-considered judgments? Think about the difference principle, which legitimizes inequalities insofar as they provide incentives for production and investment that end up benefiting the worst-off. As a result of it, there is no injustice in the fact 
that talented people claim and receive superior rewards for their contribution. Although incentivizing work (and investment) could be considered an appropriate rule of regulation, presenting it as a principle of justice may deprive us from an important critical tool. A conception of justice which does not allow us to criticize the talented for not providing a voluntary effort might be considered as insufficiently critical, or even conservative in the sense that it reinforces traits of character such as selfishness which could be the mere product of historical circumstances (Cohen, 2000, pp. 119, 120).

Now, the weakness of an approach isolating considerations of justice from all-things-considered judgments is that much of its practical relevance may be lost if no guidance is offered to make all-things-considered judgments, if after having defended the justice of equality one merely suggests that 'it might [nonetheless] be bad policy to level down' (Cohen, 2008, pp. 319, 320). Political philosophers often set themselves the mission to guide (political) action, although the impact of ideas may be low and slow. Cohen would certainly recognize this practical ambition of political philosophy, as his philosophical work has clearly been moved by a normative agenda. He spent time rebutting the principle of self-ownership because he thought it was implicit in the vernacular thought-complex which has helped to power the rightward political shift of the past quarter-century' (Cohen, 1996). He worried about the difference principle because its rationale was and still is widely used in public debates to oppose increases in taxes or justify talent-favoring inequalities. Nevertheless, in his later work on the nature of justice, he seems to have popularized a trend in political philosophy that distances itself from political practice and considers purely theoretical issues such as the fundamental value of justice taken in isolation. These theoretical issues are not necessarily devoid from practical implications, but these implications could and should be worked out.

Value pluralism combined with a lack of commitment to a principled way to adjudicate in case of a clash of different values and a very narrow conception of justice make it difficult (and sometimes impossible) for luck egalitarian theories of this stripe to guide action when values clash. Although, presumably, luck egalitarians think equality is an important value (why would one, otherwise, devote one's theory of justice to it?), without a view on how equality relates to other values it is unclear what role equality (or any other value) should play when considering what we ought to do all things considered. But what is the point of a theory of justice if it cannot guide (political) action? Is it enough to consider what justice requires as an isolated value? Granted, Rawls's approach may make too many concessions when formulating requirements of justice, but at least it is useful as a tool for the political quest of justice. Rescuing justice from more value-encompassing principles, like the ones endorsed by Rawls, will not attract many supporters if luck egalitarianism is not, in turn, rescued from practical irrelevance. $^{3}$ 


\section{What is the point of luck egalitarianism?}

Lippert-Rasmussen faces this challenge of practical irrelevance by assigning theory a modest role in the larger attempt to build all-things-considered judgments about political regulation. For an all-things-considered judgment, weighing all values appropriately, you need to take a closer look at each particular value first. This is what luck egalitarians do with the value of justice. Admittedly, this way of proceeding is perfectly legitimate. Rather than considering the theories put forth by Lippert-Rasmussen and Cohen as practically irrelevant, we should thus consider them as incomplete (p. 3). There is some practical use in studying one particular value in detail. It allows us to see what is at stake in the value, what kind of appeals to it can be justified and when a clash with another value turns out to be merely apparent after the value is properly spelled out. It may very well be that if we spell out different values properly, clashes are much rarer than is sometimes assumed, as Lippert-Rasmussen argues with regard to community, freedom and (despite its dubious status as a value) stability.

Nevertheless, we want to resist the temptation to hide one's normative commitments behind value pluralism. Lippert-Rasmussen says that'weighing different values against one another is difficult' (p. 210) and that he prefers 'not say anything about how much weight exactly should be given to luck egalitarian justice' (p. 210). Being sympathetic to luck egalitarian considerations, however, we would like its relevance and appeal to be more apparent. Downplaying the role of a theory of justice, it seems to us, will not reconcile luck egalitarianism with its discontents. In our view, it is not enough for the plausibility of a theory of justice to be consistent. It must also have some political potential. ${ }^{4}$ Otherwise, there is something gratuitous in it - which Lippert-Rasmussen recognizes and does not seem to find problematic. And although this 'gratuity' is intellectually legitimate (not all scientific work needs to have immediate practical relevance), it stands in tension with what draws many to political philosophy: the importance of social progress in the real world.

Fortunately, Lippert-Rasmussen provides us with some indications on the way toward all-things-considered judgments. His last chapter discusses several alleged clashes between luck egalitarian justice and other values and convincingly concludes that it'does not clash with freedom, demandingness, publicity or stability, though it might do so with certain forms of community' (p. 239). This discussion is useful. What is lacking is a stance on what we should do when there is a genuine clash, such as between equality and efficiency or equality and respect - the two conflicts that will be discussed in this paper. We shall explore two routes open to luck egalitarianism to guide political judgments. One route would be to stick to pluralism, but to discuss genuine clashes of value and find a satisfying rule of regulation in each case (Section 'Pluralism with rules of regulation'). Another would consist in giving up value pluralism of the kind that rules out principled adjudication, by identifying an overarching 
value or principle that would arbitrate between clashing values. We suggest that Lippert-Rasmussen's foundation of equality potentially entails such a principle (Section 'Valuable for what?').

\section{Pluralism with rules of regulation}

If we cannot find any elegant way of ranking values once and for all - which this section takes for granted but the next one challenges - it is important to think about ways of arbitrating genuine clashes. ${ }^{5}$ The clash between equality and efficiency is often seen as the most serious. Let us understand efficiency here in the restricted sense of productive efficiency, i.e. the capacity of an economic organization to boost production so as to increase aggregate wealth. Equal incomes are generally believed to be inefficient in this sense because they do not incentivize hard work, innovation and investment. Rawls's defense of the difference principle, but also, for example, Richard Arneson's move away from luck egalitarianism and his endorsement of a form of responsibility-catering prioritarianism (Arneson, 2000, p. 344) are attempts to deal with this tension. The appeal of these approaches is that they escape the leveling-down objection by incorporating a form of efficiency within their conception of justice. By doing so, though, they blur the distinction between a distributive consideration (fairness in the distribution of wealth) and an aggregative one (total amount of wealth of the least or less well off). ${ }^{6}$ Luck egalitarians, in contrast, insist on the distinction. Yet they generally deny that egalitarian justice always trumps efficiency.

On the articulation between equality and efficiency, Lippert-Rasmussen's discussion of the leveling down objection to egalitarianism is disappointing. He seems to believe that we should never level down and limits his discussion to exploring some ways in which egalitarians have struggled to counter this objection. What the reader keeps wondering is for what reasons, and under what circumstances, efficiency considerations might trump requirements of luck egalitarian justice. Should we always sacrifice equality for the benefit of the worst-off? Should we sacrifice efficiency when the worst-off cannot be benefited but others (not necessarily much better off) can (Parfit, 1997)?

One line of argument could be the following. Imagine people deciding rules of regulation under ideal conditions of discussion. In order to avoid the bias toward wealth maximization of the Rawlsian original position, where people are supposed to maximize their gains, imagine people discussing freely on the appropriate balance between equality and efficiency. People rightly value efficiency in production because they want to reduce their amount of toil and spend time doing other things than working. Productivity can be increased by sacrificing some equality. Provided that even those who become relatively worse off due to this deviation from equality value efficiency over justice, this move is legitimate. Yet at some point a society reaches a threshold of wealth and productivity that makes an important reduction of labor technically possible that 
would not make everyone worse off. It then becomes dubious that efficiency gains necessarily 'benefit' the least well off more than preserving the level of equality. If people do not merely value economic benefits (e.g. increased purchasing power) and their absolute position, but also luck egalitarian justice and their relative position, a steady-state economy with limited inequality is likely to be preferable to continued growth and deepening inequality - assuming, for simplicity's sake, that growth effectively benefits the less well off from a material point of view, which is far from evident in reality. From such a perspective, efficiency would trump equality only up to the point that some sufficiency threshold (to partly free people from toil) is reached. At that point, equality and efficiency would be in equilibrium: you cannot sacrifice some more equality for more efficiency and you cannot increase equality if it threatens the steady state.

Most people probably value both equality and wealth, but some Rawlsians and prioritarians might go too far when supposing that an increase of the wealth of the least well off or those among the less well off is always preferable to an increase of equality. ${ }^{7}$ Pareto improvements may be rational and legitimate from a democratic point of view, but they are not necessarily just, and could be resisted in the name of justice. Whether people will actually prefer justice to efficiency is another question, as they will often be tempted by a bigger share and have been socialized in societies giving primacy to work and consumption over leisure. Yet the point of this brief discussion is only to show that there are many ways of balancing justice and efficiency, and how to do so is the pressing question that egalitarians face in the real world.

It would be interesting to have Lippert-Rasmussen's views on such concrete issues. Alternatively, if he does not want to go into the details, he could select a general rule of regulation among the following: either, efficiency always trumps justice when it benefits the worst-off, or when it benefits other people without harming the worst-off, or only to a certain point - say a sufficiency threshold (Casal, 2007). This would clarify where the conception of luck egalitarianism endorsed by Lippert-Rasmussen stands compared to competing theories of justice. You could have different types of luck egalitarians: some more Rawlsian - because they accept the difference principle as a rule of regulation - some more Arnesonian - because they include more aggregative considerations in their rule of regulation - etc. Luck egalitarianism would become a partial stance on the question of justice, to be supplemented with rules of regulation.

Respect is another value which is often taken to clash with fairness but it is not explicitly discussed by Lippert-Rasmussen. Wolff (1998) has argued that this other egalitarian value - respect - might trump fairness if enforcing fairness would be too costly in terms of it. This is the case, he argues, with most policies to distinguish between the'deserving' and the 'undeserving' poor. Yet does respect for people's dignity, or concern for their self-respect always trump considerations of fairness $?^{8}$ Other people argue that it is disrespectful not to treat people with normal mental capacities as autonomous and capable of responsible choices 
(see Dworkin, 2000, 2011). But as Cohen and Lippert-Rasmussen suggest, if inequalities cannot be traced back to genuine free choices, they are unjust. Now, in the absence of certainty about free will, ${ }^{9}$ what should be our rule of regulation? Should we be ready to sacrifice fairness for respect? Respect for fairness? Should we again opt for a sufficiency threshold?

An interesting rule of regulation, articulating fairness, respect and efficiency, would be the following. As a matter of fairness, the state should try to'level the playing field' and equalize opportunities for welfare (or, in Lippert-Rasmussen's words, to equalize'the satisfaction of individual's reasonable non-instrumental concerns') by equalizing hourly wage and job opportunities and by providing free services for accommodating different needs. As a matter of respect and efficiency, it nonetheless holds individuals responsible for part of their situation (the trade-off they opt for between work and leisure). This is respectful, in Dworkin's sense, because assuming full determinism hurts people's self-respect and self-understanding of their actions (Dworkin, 2011, ch. 9). And it is efficient because it incentivizes work. Yet, in addition, a limit is set to the satisfaction of these two values: as a matter of justice, no one should fall below a sufficiency threshold covering basic needs. This can be secured via an unconditional income guarantee, which then also makes the policy respectful in Wolff's sense because people do not have to make shameful revelations to access income support. This proposal offers a clearer view of how the equalizing impulse is limited by other values and how it itself constrains the pursuit of these values. By clarifying their views on such issues, luck egalitarians might be even better placed to tackle objections based on luck egalitarianism's alleged practical implications - in particular objections from relational egalitarians.

In sum, recognizing a plurality of values does not commit anyone to value relativism ${ }^{10}$ or to intellectual retreat in the world of pure ideas. If Lippert-Rasmussen is not ready to abandon value pluralism, he could nonetheless come forth with a more complete and more appealing theory. Yet the next section challenges the very idea of value pluralism, the abandonment of which is obviously another possible strategy.

\section{Valuable for what?}

In this section, we develop another strategy to make Lippert-Rasmussen's version of luck egalitarianism capable of guiding action. Although he explicitly rejects the idea that all values have to be deducible from one source-value (pp. $10,52,53)$, we want to suggest that his view might contain the tools to offer a principled way to adjudicate in cases where values conflict.

The key for this strategy lies in chapter 2 ('Why Equality?'). In this chapter, Lippert-Rasmussen discusses a fundamental question of moral philosophy: by virtue of what are people moral equals? He offers what we call the 
grounding claim, which we argue seems to commit him to a strong position on all-things-considered judgments:

The grounding claim:'the equality of moral standing of persons is grounded in their capacity to be non-instrumentally concerned with things in a distinctive way, say, one that involves long-term planning'. (p. 51)

Non-instrumentally caring for something means that one cares for it not as a means to an end, but that one judges the thing important for its own sake. An example of something we non-instrumentally care for is our own welfare. We may also non-instrumentally care for the welfare of others, for the natural environment or for things of great beauty like works of art (p. 99). ${ }^{11}$ This answer to why equality? grounds Lippert-Rasmussen's stance on the currency of egalitarian justice debate. People should be equal in terms of 'what they are non-instrumentally concerned about' (p. 51) - and, an important addition, 'not unreasonably so' (p. 112). ${ }^{12}$

Why should people with equal moral standing have equal amounts of what they non-instrumentally care about? Lippert-Rasmussen thinks that fairness does the work here: 'treating people with equal moral standing unequally when there is no difference between them that can justify the relevant differential treatment is plainly unfair' (p. 52). We share the intuition that there are strong pro tanto fairness-based reasons to treat moral equals equally. However, as Lippert-Rasmussen admits, it is highly implausible to claim that equality (or fairness) is the only thing of value, or perhaps even the only justice-related value (p. 209), and although value conflicts with equality in the luck egalitarian sense are perhaps less frequent than is sometimes assumed, clashes with other values may be inevitable. Possible justification for unequal treatment, then, cannot be ruled out.

Lippert-Rasmussen's ground for equal moral treatment might nonetheless contain, in nuce, a way to adjudicate between different values in case of a genuine clash. If one takes a certain capacity as the foundation for moral equality, this (it seems to us) has to be connected to a very deep appreciation of this capacity. Presumably, this is because Lippert-Rasmussen thinks that it is of great moral importance to have the capacity to non-instrumentally care about things (from now on: the capacity). Lippert-Rasmussen writes (regarding the implications of his answer to the question why equality? to the equality of what? question): 'if we think the basis of equal moral standing is the capacity to experience pain and pleasure, it would be odd to think that causing pain or pleasure are irrelevant to the wrong- or right-making features' (p. 51). We suggest a variant of this claim holds true for his view: if, like Lippert-Rasmussen, we think that the capacity to non-instrumentally care about things grounds moral equality, it would be odd to claim that the extent to which this capacity is protected and can be put to good use is irrelevant to wrong-making features.

One may object that not moral equality but fairness is the reason an equal distribution is required. ${ }^{13}$ Yet, although Lippert-Rasmussen claims that fairness 
is independently grounded (or not grounded at all), there is an important sense in which his grounding claim generates fairness concerns. ${ }^{14}$ It is, after all, only among moral equals that fairness applies. As we will argue, a commitment to the grounding claim does not give rise exclusively to fairness considerations. There are three different ways ${ }^{15}$ in which equal treatment could be in tension with the grounding claim: equal treatment can undermine the capacity; equal treatment can undermine the use of the capacity; and, finally, equal treatment could undermine the extent to which people realize the goals the capacity allows them to set. To illustrate the difference, let us take people's plans in life as an example of something they non-instrumentally care about. People need the agency-conditions necessary to formulate plans, they need an environment in which they can use these capacities to formulate plans, and - finally - they need the means to pursue the plans they have made. Let us discuss each in turn.

First, one may be concerned with the protection of this capacity itself. Certainly, moral equals are entitled to the protection of their status as full members of the moral community. Yet, it is unclear that equality is always the best way to do so. Imagine two alternatives: a world where all are equally well off at very low levels (some die because their basic needs are not met) or a slightly unequal world where everybody is much better off. Having one's basic needs met is a necessary precondition for having the capacity in the first place. ${ }^{16} \mathrm{An}$ attachment to this capacity, then, in some cases overrules equality. It seems that in this case equality undermines what makes it valuable in the first place: equality at very low levels may undermine people's capacity to be non-instrumentally concerned with things. Pursuing fairness at this cost, in this particular case, goes against the spirit of what makes people moral equals and hence against what made that fairness was required in the first place. This cannot be right: equality should not be protected at the cost of what makes people eligible for equal treatment. ${ }^{17}$

Second, there is the ability to use the capacity. What is having this capacity good for, if one cannot use the capacity? The leveling down objection can be used to show why this is so. In cases of great deprivation, people may not be able to care for things in a non-instrumental way, at least not one that involves long term planning. If one is very poor, one may be constantly occupied with issues of survival. If one does not enjoy freedom of expression or freedom of conscience, one cannot formulate long term plans in life one reflectively endorses. The 'bullish stance' that Lippert-Rasmussen seems to take on the leveling down objection may be compatible with his view of justice (perhaps the poor world is 'in one way' better), but given his preferred basis for moral equality, it seems that it is morally (much) worse. Again, the tension is between equality and the grounding claim: an equal distribution may go against people using the capacity that makes them moral equals. Other principles may be better placed to protect the effective use of the capacity, like sufficiency or efficiency. One could argue that sufficiency trumps equality in this case, by pointing to how prioritizing one 
over the other relates to the capacity: sometimes sufficiency will be the best way to ensure that what makes equality valuable is protected. It is important to point out, however, that this reply does not rule out leveling down categorically: there may be situations in which everybody is quite well off and where a move to equality would not clash with the capacity.

Finally, it seems that by endorsing the grounding claim, one will have to worry about people's ability to realize or pursue the things that they non-instrumentally care for, say their long-term plans. Lippert-Rasmussen seems to be concerned with people actually attaining what they non-instrumentally care for. Placing people in a position where they can form attachment to certain things for their own sake seems inconsistent if one, afterwards, is not concerned with people's capacity to actually (try to - if one is an opportunity-egalitarian) attain or realize whatever it is they non-instrumentally care for. Lippert-Rasmussen is certainly concerned with people realizing their plans, but focuses on people's capacity to equally realize their plans. But, as Christiano and Braynen (2008) have pointed out as well, ${ }^{18}$ if one cares about the equal distribution of a thing, one has to think the thing itself is valuable as well. In this case, the thing (Lippert-Rasmussen's answer to the metric question) is success in attaining what we non-instrumentally care about. However, several other values than distributive equality may matter when thinking about people's capacity to realize their plans. Relational equality ${ }^{19}$ may be one. Lippert-Rasmussen's willingness to take satisfaction of offensive (pp. 89-91) preferences into consideration may be particularly problematic in this regard, because this allows for preferences denying each other a status as equals to count when realizing equality. ${ }^{20}$ Including racist, misogynist, or otherwise in-egalitarian preferences as if they were legitimate might have several detrimental effects, for example on people's bases of self-respect and the sense that their plans matter as much as others'.

But not only relational equality, which Lippert-Rasmussen argues can be accommodated within luck egalitarianism, should worry us here. Efficiency worries arise as well. Only some types of goods need to be equally distributed in order for people to realize the plans they non-instrumentally care for. In other cases, and with other goods at stake, a larger set of goods may be better even if this set of goods is smaller than that of others. It is unclear why a situation that is less conducive to people realizing what they non-instrumentally care for could be better because everybody is equally badly placed to realize their respective plans. Note that our appeal here is not simply an appeal to the leveling down objection, but we rather point to a tension in accepting both leveling down as required by justice and the ground for moral equality. In other words, there is a tension between what is required by justice and what makes it required by justice. At the very least, this ground for equality commits a luck egalitarian to saying that a world in which everybody is equally badly off (everybody fails to see the things they non-instrumentally care for materialize) is worse than a world in which everybody is equally well off but sees their plans of life fulfilled. One 
may reasonably claim that institutions that treat people as moral equals (realizing relational equality) and allow for certain inequalities are more conducive to people attaining what they non-instrumentally care for. Again, if strict equality leads to a situation where people are less well placed to put the capacity to good use, this is inconsistent with the grounding claim.

Besides the three ways in which a concern for the capacity tells us something about how conflicts between values should be dealt with, it gives us priority rules as well. Not priority rules that rank different values over each other (say, freedom always trumps equality), but a lexicographic ranking, by looking at the importance of what the different values at work are protecting. The preconditions for the capacity have to be protected first and foremost. Without it, the other two (using and acting on the results) are impossible to begin with. Using the capacity - making long-term plans - is more important than the capacity to realize the plans, since one cannot realize plans one did not make. This priority does not have to be a strict one. Once people have their capacity to make plans well protected, they may benefit more from increasing the amounts of goods to pursue their plans than from a stronger protection of basic rights. The kind of priority order proposed here avoids the implausible claim that one particular value always takes priority over all other values. When confronted with value conflicts, we should not only look at the value at stake, but also at what we are protecting by protecting the value.

As we have tried to show, equality is not the only value that has a clear connection with the fundamental capacity and, sometimes, it cannot - given the grounding claim - be the most important one. In certain circumstances, and when certain goods are at stake, equality is the best way to protect this particular capacity. This is arguably true for political power or equal treatment under the law. But in other circumstances, or for other goods, other values may be more important for the protection of people's capacity to non-instrumentally care for things, to use the capacity, and to realize the plans that result from the use of the capacity. If this is right, we need a plausible interpretation of what this capacity consists in exactly, and what is needed to protect, use, and pursue it.

One could treat this proposal in two ways. First, one could try to construct some kind of Lippert-Rasmussian foundationalism: treating the capacity to non-instrumentally care for things as the ground from which all other values flow. Something, on such a view, would only be valuable if - and in so far as - it protects the capacity. A reductive view like this, finding a common ground for all values, is an option that Lippert-Rasmussen seems to find unattractive (pp. 52, 53). He argues that even if it is a legitimate complaint against his view that some values are ungrounded, it is a complaint that equally holds for all other views. We think that one may be more ambitious here: where other views have difficulties with grounding values, Lippert-Rasmussen's might offer a possible ground for a principled approach to clashes of values. Second, if one insists on value pluralism, one could treat the capacity as one value among others, but as 
a very important one - at least important enough to be a reason to treat people as moral equals. In balancing what different values require, this could serve as an anchor when reaching reflective equilibrium.

We did not aim to show that there is no plurality of incommensurable values (the proposal made in this section does not entail monism), and neither does it entail a strict (or even loose) lexical ordering of different values. Neither is the view proposed here committed to something like Dworkin's version of holism, which would require us to interpret values in such a way that all values are compatible (see Dworkin, 2011; Lippert-Rasmussen, 2015, p. 232). Finally, this section does neither entail that justice has to be understood as luck egalitarian equality, or that justice goes beyond luck egalitarian equality alone. One, for reasons not discussed here, might want to retain the powerful concept of justice for what we should do all-things-considered for political reasons. ${ }^{21}$ But for the purposes of our argument, one can keep justice as one value which then feeds into whatever one needs to do all-things-considered (act in the morally right way? Realize'Schmustice?'). This way, one can still claim that natural inequalities are unjust (rather than merely regrettable). Although we do not necessarily agree with Lippert-Rasmussen's approach to these questions, our arguments in this section do not bear on them. We propose that there might be a way to adjudicate between different values by appeal to reasons Lippert-Rasmussen himself endorses, given that it flows from his preferred ground for moral equality.

\section{Conclusion}

In this paper, we have proposed two ways in which luck egalitarianism in general, and Lippert-Rasmussen's version of it specifically, could be made more robust against the challenge of practical irrelevance. Because we are sympathetic to the main claims of luck egalitarian justice and concerned with its philosophical and political appeal, we think that prominent defenders of luck egalitarianism should not hide behind value pluralism or behind a purely abstract and narrow approach to justice (figuring out the intricacies of one particular concept). More importantly, we think luck egalitarians have no convincing reason to do so: they have plenty of means at their disposal to think about how to embed equality of luck in a wider and more ambitious theory. A defense of luck egalitarianism is incomplete, and perhaps even unappealing without this wider view.

In sum, we do not believe that it is impossible to find appropriate rules of regulation for the few genuine conflicts of value that one may encounter. Of course, it requires more normative commitment on difficult issues - and not the least a clarification of the policies entailed by luck egalitarianism. But we believe this is the main task of political philosophy - and that luck egalitarianism (including Lippert-Rasmussen's version) may be perfectly able to take on this task. 


\section{Notes}

1. This view can be held to be more egalitarian on the assumption that very few inequalities can be justified by appeal to choice (see Barry, 2005). Otherwise, as luck egalitarianism is more choice-sensitive than the Rawlsian principles, it could also be - in one way - more inegalitarian, which is the assumption on which many critics from the left base their objection to luck egalitarianism.

2. Temkin (2000) is another example of such egalitarian value pluralism. He concludes his discussion of the leveling down objection to equality by saying that the 'main lesson [...] is that we should be pluralists about morality' (p. 155).

3. We are not the first to notice this, of course. e.g. Schemmel $(2007$, p. 63) says: 'The luck egalitarian principle is so strong and insensitive to moral complexity that its status as a principle of justice is unclear, both for the domestic case and for the global case'.

4. See Axelsen and Bidadanure (in press).

5. Arbitrating is different from ordering once and for all. It is a matter of regulation and the guidelines provided may lack the philosophical foundation of principles of justice. Pluralists may reject definitive orderings, but this does not make arbitrations impossible. It is just a matter of decision, grounded in various considerations, including but not exhausted by justice.

6. On this distinction, see Barry, 1965, pp. 43, 44.

7. Rawls himself seems attracted by Mill's ideal of a steady-state economy (see Rawls, 1999, p. 107, fn. 33), so he might not always recommend maximizing the prospects of the least well off. Or maybe he thinks that maximizing the prospects of the least well off in terms of primary goods requires at some point to sacrifice wealth for leisure. Moreover, the amount of inequality compatible with what Rawls calls 'perhaps the most important primary good' $(1971, \S 67)$, the social bases of self-respect, may also be limited. This is another way in which the amount of inequalities permitted by a Rawlsian theory would be constrained.

8. An alternative way of responding to the challenge, suggested by Wolff himself, would be to include respect within the currency of egalitarian justice and thus consider the distribution of welfare as a matter of fairness. Hence egalitarian policies that hurt people's self-respect would be precluded by a commitment to equalize (opportunities for) welfare (Wolff, 1998). As Lippert-Rasmussen's metric of egalitarian justice includes - yet is not exhausted by - welfare (pp. 98-101), this line of argument is available to him. However, it does not make the tension disappear; it only becomes an internal tension between two aspects of fairness which are the responsibility sensitivity and the equalization of (opportunities for) welfare. The appropriate balance must still be found.

9. Dworkin does not think that the uncertainty about free will should bother us because our attribution of responsibility to people does not depend on empirical facts. Contrary to Cohen, he defends the compatibilist view that moral responsibility is compatible with full determinism. See Dworkin, 2011, ch. 10.

10. Value pluralism is the mere recognition of a plurality of basic values independent from one another. Value relativism is the idea that those values are incommensurable.

11. See Stemplowska (in press) for a discussion of this.

12. We think the capacity is best understood as a range property. However, within the range, people's capacity to non-instrumentally care for things itself is a scalar capacity: people may be closer or further away from the minimal level. LippertRasmussen's claim has to be that although people are not equal in having the 
capacity, as long as they are within the range they are moral equals. Of course, this raises questions about the acceptability of taking a range property, which supervenes on a scalar property (Carter, 2011). Lippert-Rasmussen discusses Carter's challenge with respect to Rawls' $(1971, \S 77)$ preferred range property and criticizes Carter's proposal for being vulnerable to his own objection (p. 47), but he does not discuss how his preferred standard fares in light of this challenge. He merely points out that the worries about a luck egalitarian grounding of moral equality are no'reason to reject egalitarianism, since other distributive theories involve similar problems' (p. 51). Although we do not find this reply very satisfying, we lack space to discuss this issue here.

13. We thank the anonymous reviewers for pressing us to clarify this.

14. More can be said about the relationship between moral equality and fairness, but unfortunately we cannot do so here.

15. These three levels at which equality may be bad loosely follow Rawls' distinction between the basic needs which need to be covered to protect the fair value of basic liberties (Casal, 2007, 323; Rawls, 2005, 228), the first principle which aims to protect people's moral powers (Casal, 2007, 324; Rawls, 2005) and the second principle (which aims to distribute those goods people need to pursue their plans in life) (Rawls, 1971, 92).

16. See e.g. Casal, 2007, for why basic needs have priority in a Rawlsian theory of justice over the first principle of justice.

17. This argument is structurally similar to Christiano and Braynen $(2008,398)$ 's claim that those who value equality of something do so because they value that thing. Thus they prefer more of that thing to less; otherwise they would not bother with its distribution. Hence, wanting equality of that thing entails a refusal to level down: even if inequalities are always unjust, some equalities are even more unjust than some inequalities when compared with an ideal distribution which is both equal and Pareto optimal. Our claim is that if one grounds the moral equality in the capacity, one must value the capacity itself. And if one values the capacity one does not only value equality in the realization of one's goals, but one cares about the realization of the goals (which sometimes requires equality, sometimes something else). We thank an anonymous reviewer for insisting that we clarify the similarities and differences between our view and Christiano and Braynen's.

18. Note, however, that accepting Christiano and Braynen's proposal does not necessarily entail giving up on pluralism, whereas the approach we suggest here does entail that, because it takes the value of the capacity as foundational.

19. Understood, for example, as being able to relate to your fellow citizens as equals (see Anderson, 1999; Axelsen and Bidadanure, in press).

20. We find Lippert-Rasmussen's claim that offensive preferences can be included surprising, especially given that he thinks we should protect what people care about non instrumentally'not unreasonably so'. This raises the question what it means to have racist, misogynist or otherwise offensive preferences'reasonably so'.

21. See Axelsen and Bidadanure (in press).

\section{Acknowledgments}

We'd like to thank Anahi Wiedenbrug, David Axelsen, Juliana Bidadanure, Kasper LippertRasmussen, Sara Amighetti, Tom Parr and audiences at the University of Louvain and the London School of Economics where earlier drafts of this paper were presented for their 
questions and comments. We also want to thank the two anonymous referees for this journal for their constructive comments and suggestions.

\section{Disclosure statement}

No potential conflict of interest was reported by the authors.

\section{Notes on contributors}

Tim Meijers is an assistant professor at Leiden University and a postdoctoral researcher on the ERC Fair Limits project at Utrecht University. He obtained his PhD from the University of Louvain (Hoover Chair). He writes on intergenerational justice, family ethics, reproductive rights, agents of justice and the ethics of migration.

Pierre-Etienne Vandamme recently defended his PhD thesis entitled The Democratic Road to Justice at the Hoover Chair of Economic and Social Ethics (University of Louvain, Belgium). His research interests include theories of justice, democratic theory and civic education.

\section{References}

Anderson, E. S. (1999). What is the point of equality? Ethics, 109(2), 287-337.

Arneson, R. (2000). Luck egalitarianism and prioritarianism. Ethics, 110(2), 339-349.

Axelsen, D., \& Bidadanure, J. (in press). Unequally egalitarian? Critical Review of International Social and Political Philosophy, 22(3).

Barry, B. (1965). Political argument. London: Routledge and Kegan Paul.

Barry, B. (2005). Why social justice matters. Cambridge: Polity Press.

Carter, I. (2011). Respect and the basis of equality. Ethics, 121(3), 538-571.

Casal, P. (2007). Why sufficiency is not enough. Ethics, 117(2), 296-326.

Christiano, T., \& Braynen, W. (2008). Inequality, Injustice and levelling down. Ratio, 21(4), 392-420.

Cohen, G. A. (1996, November 8). Self-ownership and the libertarian challenge. Times Literary Supplement.

Cohen, G. A. (2000). If you're an egalitarian, how come you're so rich?. Cambridge, MA: Harvard University Press.

Cohen, G. A. (2008). Rescuing justice and equality. Cambridge, MA: Harvard University Press.

Dworkin, R. (2000). Sovereign virtue: The theory and practice of equality. Cambridge, MA: Harvard University Press.

Dworkin, R. (2011). Justice for hedgehogs. Cambridge, MA: Harvard University Press.

Lippert-Rasmussen, K. (2015). Luck egalitarianism. London: Bloomsbury.

Parfit, D. (1997). Equality and priority. Ratio, 10(3), 202-221.

Rawls, J. (1971). A theory of justice. Cambridge, MA: Harvard University Press.

Rawls, J. (1999). The Law of Peoples. Cambridge, MA: Harvard University Press.

Rawls, J. (2005). Political liberalism. New York, NY: Columbia University Press.

Schemmel, C. (2007). On the usefulness of luck egalitarian arguments for global justice. Global Justice: Theory Practice Rhetoric, 1, 54-67. 
Stemplowska, Z. (in press). How generous should egalitarians be? Critical Review of International Social and Political Philosophy, 22(3). doi:10.1080/13698230.2018.1438 785.

Temkin, L. (2000). Equality, priority, and the levelling down objection. In M. Clayton \& A. Williams (Eds.), The ideal of equality (pp. 126-161). London: Macmillan.

Wolff, J. (1998). Fairness, respect, and the egalitarian ethos. Philosophy \& Public Affairs, 27, 97-122. 